\title{
A History of Mild Traumatic Brain Injury Affects Peripheral Pulse Oximetry during Normobaric Hypoxia
}

\author{
Leonard A. Temme ${ }^{1 *}$, Paul St. Onge ${ }^{1,2}$ and Joseph Bleiberg ${ }^{3}$ \\ ${ }^{1}$ U.S. Army Aeromedical Research Laboratory, Fort Rucker, AL, USA, ${ }^{2}$ Laulima Government Solutions, LLC, Orlando, FL, \\ USA, ${ }^{3}$ National Intrepid Center of Excellence, Walter Reed National Military Medical Center, Bethesda, MD, USA
}

Introduction: Physiological and emotional stressors increase symptoms of concussion in recently injured individuals and both forms of stress-induced symptoms in people recovering from mild traumatic brain injury (mTBI), but who are asymptomatic when not stressed or are at rest.

Methods: Healthy asymptomatic adults (25.0 \pm 5.1 years) with a history of mTBI $(n=36)$ and matched healthy controls $(\mathrm{HC})(n=36)$ with no mTBI history were exposed to three levels of normobaric hypoxic stress generated with the Reduced Oxygen Breathing

OPEN ACCESS

Edited by:

Kenneth Curley, latrikos Research and Development

Solutions, LLC, USA

Reviewed by:

Ralph George Depalma, Department of Veterans Affairs Office of Research and Development, USA

Elham Abbasloo,

Physiology Research

Center Kerman, Iran

${ }^{*}$ Correspondence:

Leonard A. Temme

leonard.a.temme.civ@mail.mil

Specialty section: This article was submitted to Neurotrauma,

a section of the journa

Frontiers in Neurology

Received: 27 June 2016 Accepted: 31 August 2016 Published: 21 September 2016

Citation:

Temme LA, St. Onge $P$ and Bleiberg J (2016) A History of Mild

Traumatic Brain Injury Affects Peripheral Pulse Oximetry during Normobaric Hypoxia. Front. Neurol. 7:149. doi: 10.3389/fneur.2016.00149 Device (ROBD) (Environics, Inc., Tollande, CT, USA), which reduced the percent $\mathrm{O}_{2}$ by mixing sea level air with nitrogen. The ROBD reduced the percent $\mathrm{O}_{2}$ in the breathable air from the normal $21 \%$ to $15.5 \% \mathrm{O}_{2}, 14 \% \mathrm{O}_{2}$, and $13 \% \mathrm{O}_{2}$. Under these conditions: (a) a standard pulse oximeter recorded peripheral oxygen saturation $\left(\mathrm{SpO}_{2}\right)$ and pulse rate (beats per minute) and (b) the Functional Impairment Tester (FIT) (PMI, Inc., Rockville, MD, USA) recorded saccadic velocity and pupillary response dynamics to a brief light flash.

Results: For all three hypoxic stress conditions, the mTBI group had significantly higher $\mathrm{SpO}_{2}$ during the final minute of exposure than did the controls $[F(2.17,151.8)=5.29, p<0.001$, $\left.\eta^{2}=0.852\right]$ and the rate of $\mathrm{SpO}_{2}$ change over time was significantly shallower for the mTBI than for the controls $\left[F(2.3,161.3)=2.863, p<0.001, \eta^{2}=0.569\right]$, Greenhouse-Geisser corrected. Overall, mTBI had lower pulse rate but the difference was only significant for the $14 \% \mathrm{O}_{2}$ condition. FIT oculomotor measures were not sensitive to group differences. When exposed to mild or moderate normobaric hypoxic stress $\left(15 \% \mathrm{O}_{2}\right)$ : (1) $\mathrm{SpO}_{2}$ differences emerged between the mTBI and matched HC groups, (2) heart rate trended lower in the mTBI group, and (3) FIT measures were not sensitive to group differences.

Conclusion: A relatively minor hypoxic challenge can reveal measurable differences in $\mathrm{SpO}_{2}$ and heart rate in otherwise asymptomatic individuals with a history of mTBI.

Keywords: mild traumatic brain injury, normobaric hypoxia, pulse oximetry, Functional Impairment Tester, oculometric, stress

\section{INTRODUCTION}

Physiological or emotional stressors can increase symptoms of mild traumatic brain injury (mTBI) in recently injured individuals, and either type of stress can induce symptoms in individuals with mTBI who are asymptomatic when not stressed (1). For example, compared to groups of normal controls, mTBI groups showed higher heart rate $(2)$ and decreased heart rate variability (HRV) $(3,4)$ as well 
as reduced cerebrovascular reactivity and lower end-tidal carbon dioxide $\left(\mathrm{PETCO}_{2}\right)$ trends $(5,6)$ in response to experimental stress. The stressors used in these experiments included exercise $(3,7)$, repeated breath holds and hyperventilation $(5,6)$, psychosocial stress (8), and mental arithmetic under conditions of noise and bright lights (2).

Hypoxia is a physiological stressor that may be readily encountered in daily life and can be relatively easily and reliably generated in a controlled laboratory setting, thus permitting precise quantification of the hypoxic physiological stressor and its effects on the volunteer. Ewing et al. (9), using an altitude chamber to generate altitude-related hypoxia, exposed a group of controls and a group of asymptomatic, concussed individuals to a simulated altitude of $3,800 \mathrm{~m}$ (nearly $12,500 \mathrm{ft}$ ). These authors reported finding a significant cognitive performance deficit in the brain-injured group at altitude, a difference which disappeared when the subjects were returned to ground level. Temme et al. $(10,11)$ extended the Ewing et al. study using normobaric hypoxia $(\mathrm{NH})$ rather than an altitude chamber to generate hypoxic stress. $\mathrm{NH}$ mixes nitrogen $\left(\mathrm{N}_{2}\right)$ with mean sea level (MSL) air to reduce the percentage of inspired oxygen from the normal sea level value of $21 \%$, a technique that is widely used in current respiratory physiology. Temme et al. found (1) at MSL, there were no differences between the mTBI and control groups in cognitive performance; (2) exposure to $\mathrm{NH}$ with $15.5 \% \mathrm{O}_{2}, 14 \% \mathrm{O}_{2}$, and $13 \% \mathrm{O}_{2}$ (approximately equivalent to breathing air encountered at $8,000,12,000$, and $14,000 \mathrm{ft}$ above MSL, respectively) resulted in a decrease in cognitive performance for both groups; (3) when hypoxic, the visual short-term memory of the mTBI group was significantly poorer than that of the control group; and (4) there was no difference between the groups on returning to $21 \% \mathrm{O}_{2}$, normal MSL air. These studies support the idea that NH is an effective stressor that can uncover symptoms of mTBI in individuals who are asymptomatic when unstressed.

Eye movements are a sensitive indicator of mTBI and can provide a great deal of objective diagnostic information about the concussed brain (12-15). Recently, instrumentation to measure a pupil's response to light flashes, and the eye's ballistic movements, saccades, was integrated into a device designed to screen for physiological impairments due to fatigue, sleep deprivation, drug and alcohol intoxication, and other physiological stressors (16-21). The device, the Functional Impairment Tester (FIT), measures ocular motility along four dimensions: pupil diameter in the dark, the latency of the pupil's response to flashes of light, the pupil's amplitude of constriction, and the eye's saccadic velocity $(17,18,20)$. The literature reports that these dimensions of the pupil, i.e., the pupillary light reflex (22) and the eye's saccadic behavior (12), can be affected by mTBI. Moreover, FIT measures have demonstrated sensitivity to hypoxia (17). To date, however, the FIT has not been established as an assessment or screening tool for concussion or mTBI. Since the behavior of the eye is a standard clinical indicator of brain injury and since vision deteriorates with hypoxia, the FIT was selected as a potential non-subjective oculomotor test to differentiate between controls and mTBI subjects during NH stress. The present study extends the Temme et al. (10) cognitive finding by evaluating response differences to $\mathrm{NH}$ between the mTBI group and the matched healthy control (HC) group in the physiological measures of peripheral oxygen saturation $\left(\mathrm{SpO}_{2}\right)$ and pulse rate, as well as oculometric.

\section{MATERIALS AND METHODS}

The volunteers and the procedures used in this study were described previously in detail by Temme et al. (10). The study was reviewed, approved, and conducted in accordance with all Federal and State laws, regulations, and standards of practice, and in accordance with all Department of Defense and U.S. Army regulations and procedures. The research protocol was approved by the Chesapeake Institutional Review Board, the U.S. Army Aeromedical Research Laboratory Human Use Committee, and the U.S. Army Medical Research and Materiel Command Human Subjects Research Review Board. The study was determined to pose a greater than minimal risk to the subjects; and as part of risk mitigation, the $\mathrm{NH}$ stress conditions were presented in an increasing sequence of severity with each subject being observed at a lower stress condition before being exposed to a greater stress.

\section{Experimental Design}

The experimental design was a two-factor mixed model with two levels of the between-subject variable and five levels of the within-subject variable. The between-subject variable was mTBI history, with one group of subjects having an mTBI history and one group without. The within-subject variable was percent $\mathrm{O}_{2}$ of the inspired air; all subjects were exposed to five levels, in the following order: $21 \% \mathrm{O}_{2}$ Baseline, $15.5 \% \mathrm{O}_{2}, 14 \% \mathrm{O}_{2}, 13 \% \mathrm{O}_{2}$, and $21 \% \mathrm{O}_{2}$ Post NH Stress.

\section{Human Subject Volunteers}

All subjects were screened by the study physician to ensure compliance with the following exclusion criteria: pregnancy; history of drug or alcohol abuse; depression; bipolar disorder; schizophrenia; problems with the heart, kidney, liver, asthma, strokes, mini-strokes, or poor leg circulation; any ongoing medical problems; current or past neurological problems such as seizures, epilepsy, or dementia; post-traumatic headache; current concentration and/or memory problems caused by a head injury; loss of consciousness $>30 \mathrm{~min}$ at the time of injury; or post-traumatic amnesia $>24 \mathrm{~h}$ at the time of injury.

For inclusion into the mTBI group, subjects met criteria that closely followed the criteria of the American Congress of Rehabilitation Medicine (23); a duration of a loss of consciousness of no more than $30 \mathrm{~min}$ at the time of the TBI, a duration of posttraumatic amnesia of no more than $24 \mathrm{~h}$, a Glasgow Coma Score of 13-15 (24), and a clinical history consistent with the diagnosis of mTBI. All members of the control group denied any history of concussion or brain injury, and each $\mathrm{HC}$ was matched with a member of the mTBI group on the basis of gender, age, body mass index (BMI), and smoking behavior (either 0 to 9 cigarettes a day or 10 or more cigarettes a day). Each group consisted of 9 women and 27 men for a total of 36 subjects per group. Each member of the matched pair of mTBI and HC was tested within a week of each other in order to minimize possible inadvertent differences 
due to drift in instrumentation, methodology, procedures, and personnel changes.

Table 1 provides the mean and SD by group of age, weight, height, BMI, resting systolic and diastolic blood pressure, pulse rate, and respiration rate. An analysis of variance showed that the mTBI and HC groups did not differ statistically along any of the parameters in Table 1; the probabilities ( $p$-values) for these comparisons ranged from a high of 0.817 to a low of 0.180 , all larger than 0.05 .

Of the 36 mTBIs, 11 were associated with sports injuries, 9 with motor vehicle accidents, 8 with falls, 5 with other concussive events, 2 were not specified, and 1 with an improvised explosive device. Of these, 19 were associated with a loss of consciousness reported to last on average about $3 \mathrm{~min}$, and 5 were associated with amnesia reported to last on average about $45 \mathrm{~min}$. The average estimated age at the time of trauma was 23 years with a SD of 7 years, and the average estimated interval between trauma and testing was 3.3 years with a SD of 2.8 years (11).

\section{Instrumentation \\ Reduced Oxygen Breathing Device-2 with Integrated Pulse Oximeter}

The NH stress was generated using the Reduced Oxygen Breathing Device (ROBD)-2 (Environics, Inc., Tollande, CT, USA), a commercial, off-the-shelf, portable, computerized, gas-blending instrument that mixes $\mathrm{N}_{2}$ with MSL air to produce breathable air with oxygen partial pressures comparable to oxygen partial pressures encountered at known altitudes (25-28). These air-nitrogen mixes are precise and repeatable and are used to induce $\mathrm{NH}$ safely, without risk of barotrauma or decompression sickness (Bends), and without using bagged mixed gases, which can be exhausted before all testing procedures have been completed. The ROBD instrumentation permits extensive laboratory testing without the complications associated with altitude chambers. In addition to MSL air, the ROBD generated three levels of NH stress. One was with a $15.5 \% \mathrm{O}_{2}$ balanced with $84.5 \% \mathrm{~N}_{2}$. The second was a $14 \%$ $\mathrm{O}_{2}$ balanced with $86 \% \mathrm{~N}_{2}$. The third was a $13 \% \mathrm{O}_{2}$ balanced with $87 \% \mathrm{~N}_{2}$. These approximated the percent $\mathrm{O}_{2}$ encountered at 8,000 , 12,000 and $14,000 \mathrm{ft}$ above MSL, respectively.

The ROBD includes a built-in conventional pulse oximeter to monitor $\mathrm{SpO}_{2}$ and pulse rate at either the subject's finger or ear lobe. $\mathrm{SpO}_{2}$ and pulse rate were recorded once every minute of testing throughout the entire test sequence.

TABLE 1 | Summary of the characteristics of the mTBI and HC groups ( $n=36 /$ group).

\begin{tabular}{|c|c|c|c|c|c|}
\hline & Group & $M \pm S D$ & & Group & $M_{ \pm} S D$ \\
\hline $\begin{array}{l}\text { Age } \\
\text { (years) }\end{array}$ & $\begin{array}{l}\mathrm{mTBl} \\
\mathrm{HC}\end{array}$ & $\begin{array}{l}25.25 \pm 5.42 \\
24.89 \pm 4.94\end{array}$ & $\begin{array}{l}\text { Systolic } \\
(\mathrm{mmHg})\end{array}$ & $\begin{array}{l}\mathrm{mTBI} \\
\mathrm{HC}\end{array}$ & $\begin{array}{l}120.14 \pm 14.79 \\
120.94 \pm 17.62\end{array}$ \\
\hline $\begin{array}{l}\text { Weight } \\
(\mathrm{kg})\end{array}$ & $\begin{array}{l}\mathrm{mTBl} \\
\mathrm{HC}\end{array}$ & $\begin{array}{l}90.75 \pm 29.42 \\
95.70 \pm 38.84\end{array}$ & $\begin{array}{l}\text { Diastolic } \\
(\mathrm{mmHg})\end{array}$ & $\begin{array}{l}\mathrm{mTBl} \\
\mathrm{HC}\end{array}$ & $\begin{array}{l}73.89 \pm 9.79 \\
73.36 \pm 7.78\end{array}$ \\
\hline $\begin{array}{l}\text { Height } \\
(\mathrm{m})\end{array}$ & $\begin{array}{l}\mathrm{mTBl} \\
\mathrm{HC}\end{array}$ & $\begin{array}{l}1.76 \pm 0.11 \\
1.77 \pm 0.09\end{array}$ & $\begin{array}{l}\text { Pulse rate } \\
\text { (beats/min) }\end{array}$ & $\begin{array}{l}\mathrm{mTBl} \\
\mathrm{HC}\end{array}$ & $\begin{array}{l}70.81 \pm 11.57 \\
72.72 \pm 14.23\end{array}$ \\
\hline $\begin{array}{l}\mathrm{BMI} \\
\left(\mathrm{m} / \mathrm{kg}^{2}\right)\end{array}$ & $\begin{array}{l}\mathrm{mTBl} \\
\mathrm{HC}\end{array}$ & $\begin{array}{l}28.32 \pm 7.87 \\
29.74 \pm 11.49\end{array}$ & $\begin{array}{l}\text { Respiration } \\
\text { (breaths/s) }\end{array}$ & $\begin{array}{l}\mathrm{mTBI} \\
\mathrm{HC}\end{array}$ & $\begin{array}{l}14.17 \pm 4.18 \\
16.92 \pm 11.45\end{array}$ \\
\hline
\end{tabular}

\section{Functional Impairment Tester}

The FIT (PMI, Inc., Rockville, MD, USA) is a commercial, off-theshelf, screening device designed to assess oculometrics (i.e., eye movements and pupillometry) as a sign of neurological changes associated with drugs, alcohol, sleepiness, or other neurological deficits that express themselves in the reflexive oculomotor behavior of the eye $(17,18,20,29)$.

The FIT records the saccadic velocity of the eye as it shifts gaze between a pair of alternately flashing lights. The FIT also records pupil diameter in the dark, the latency of the pupil's response to a flash of light, and the amplitude of that response, which is the difference between the pupil's diameter in the dark and pupil's peak constriction to the light flash. These four FIT measurements are made consecutively and require approximately a minute to complete. The FIT makes these measurements by analyzing infrared video images of the eye's cornea, lens, and pupil.

The FIT was administered twice for each of the experimental conditions. The first FIT administration started 1 min into the experimental condition; the second FIT administration started after the psychometric evaluations had been completed for that experimental condition, which was on average about 13 min after the condition began. The results reported here are of the second FIT administration.

\section{Procedure}

Individuals who responded to recruitment flyers were initially screened by phone. Potential study participants who met the inclusion criteria attended a single test session. During the test session, subjects first underwent the informed consent process. After consenting to participate in the study, subjects were medically screened by the study physician to verify self-reported health status. Female subjects provided a urine sample for pregnancy testing. The study physician ensured compliance with all inclusion/exclusion medical criteria.

After medical screening, the subject completed a set of practice FIT measures and a battery of psychometric evaluations before being connected to the ROBD. Five successful FIT practice trials were completed to ensure that the subject understood how the test worked and to make alignment adjustments to ensure that the subject was comfortable. The first three of these five FIT practice trials were completed without the subject being connected to the ROBD. For the last two FIT practice trials, the subject was fitted with the finger pulse oximeter sensor and the ROBD respirator (11). Once the correct sized respirator was securely attached to the face, the respirator was checked for leakage. If there was leakage or if the respirator did not fit or was uncomfortable, adjustments were made to fit the respirator properly. The fifth and last FIT warm-up trial was conducted with the ROBD turned on but not connected to the respirator; in this way, the subject would know what noises to expect during testing. Following these five FIT practice trials, formal testing began. Subjects were instructed to breathe normally. They were watched to ensure normal breathing and to guard against hypoventilation, hyperventilation, and hypocapnia. Every subject went through the same sequence of five conditions: $21 \% \mathrm{O}_{2}$ Baseline, $15.5 \% \mathrm{O}_{2}, 14 \% \mathrm{O}_{2}, 13 \% \mathrm{O}_{2}$, and $21 \% \mathrm{O}_{2}$ Post Stress. The volunteer acclimated to each condition for $1 \mathrm{~min}$ before beginning the following sequence of testing: 
(1) FIT measures, (2) psychometric battery, and (3) a second set of FIT measures. The results of the psychometric battery were reported previously (10).

When the testing sequence was completed for each condition, the subject was returned to $21 \% \mathrm{O}_{2}$ and allowed to take a break; if desired, the mask was removed for the volunteer to breathe normal room air. When the volunteer was ready to continue, ROBD airflow was resumed and the subject again donned the mask, which was checked to make sure the seal was tight. If the volunteer opted to continue testing without a break, the volunteer rested at $21 \% \mathrm{O}_{2}$ for at least $1 \mathrm{~min}$ before exposure to the next condition. This procedure was repeated for each of the five breathing conditions. After the subject completed all five conditions, the subject was observed in the laboratory for at least $30 \mathrm{~min}$ to ensure that there were no signs of aftereffects of the hypoxic experience. These procedures took approximately $4 \mathrm{~h}$ to complete. All subjects were tested one at a time, and testing required two laboratory technicians. It may be noted that although the laboratory technicians knew whether the specific subject was an mTBI or HC volunteer, the technicians had no knowledge of the hypothesis being investigated.

For each subject, the duration of a condition depended on the length of time the subject needed to complete the scheduled measurements for the condition. Table 2 presents the average time (in minutes) needed to complete the measurements for each of the five conditions, the two groups of subjects, and for all subjects combined. An ANOVA showed that there were no statistically significant differences between subject groups or conditions.

\section{Statistical Analysis \\ Data Reduction}

$\mathrm{SpO}_{2}$ and pulse rate were recorded by hand once a minute onto paper data collection sheets and subsequently entered into a computer for analyses. The FIT data were downloaded from the FIT software into a computer database and organized for analyses. All statistical analyses were performed with SPSS Statistics 20 (IBM Corp., Armonk, NY, USA). Alpha was set at the 0.05 level for all statistical evaluations.

\section{Multiple Analyses of Variance}

Standard multivariate analysis techniques were used to evaluate statistical significance of the results in order to control possible correlational dependencies among the numerous response

\begin{tabular}{|c|c|c|c|c|c|c|}
\hline Group & $\begin{array}{c}21 \% \mathrm{O}_{2} \\
\text { baseline }\end{array}$ & $15.5 \% \mathrm{O}_{2}$ & $14 \% \mathrm{O}_{2}$ & $13 \% O_{2}$ & $\begin{array}{c}21 \% \mathrm{O}_{2} \\
\text { post stress }\end{array}$ & Total $^{\mathrm{a}}$ \\
\hline mTBI & 14.11 & 13.70 & 14.20 & 13.90 & 13.90 & 84.70 \\
\hline $\mathrm{HC}$ & 13.86 & 14.50 & 14.20 & 13.40 & 13.60 & 83.10 \\
\hline Total mean & 14.90 & 14.10 & 14.20 & 13.70 & 13.80 & 83.90 \\
\hline
\end{tabular}

${ }^{a}$ Note that the column named Total refers to the duration of the whole data collection session, which included rest breaks between tested conditions; consequently, the total durations are longer than the sum of the durations of the five conditions. parameters. Three Multiple Analyses of Variance (MANOVAs) were conducted. The first MANOVA (Table 3) simultaneously evaluated the influence of three independent variables on the dependent variables of $\mathrm{SpO}_{2}$ and pulse rate. The three independent variables were the between-subjects variable group (mTBI vs. $\mathrm{HC}$ ), the within-subjects variable of the five percent $\mathrm{O}_{2}$ conditions, and the within-subjects variable time (the first and the last minute of the NH exposure). For the second MANOVA (Table 5), a linear regression (see next section) was first calculated as a function of the exposure time for each $\mathrm{NH}$ condition separately for the two subject groups. These regression calculations produced an intercept and slope for both subject groups for each of the five conditions. The MANOVA then evaluated whether these intercepts and slopes differed between groups (mTBI vs. HC) and the five percent $\mathrm{O}_{2}$ conditions. The third MANOVA (Table 7) simultaneously evaluated the influence of two independent variables, namely, group (mTBI vs. $\mathrm{HC}$ ) and the five percent $\mathrm{O}_{2}$ conditions, on the four oculometric FIT response variables of Pupil Diameter, Pupil Constriction Amplitude, Pupil Constriction Latency, and Saccadic Velocity.

As is standard practice with such multivariate procedures, Box's $M$ test was calculated to assess the equality of the covariance matrices associated with each of the MANOVAs. If Box's $M$ test was not significant, the covariance matrices were considered equivalent, and the significance of the differences in the MANOVA was evaluated with the Wilk's $\lambda$ statistic. If Box's $M$ was significant, the covariance matrices were deemed different, and the significance of the differences in the MANOVA was evaluated with Pillai's trace.

For the MANOVAs reported in Tables 3, 5 and 7, univariate follow-up evaluations are reported in Tables 4, 6 and $\mathbf{8}$, respectively, along with the group by condition average and SEM. When univariate interactions between group and the other independent variables emerged significant, planned comparisons were performed to evaluate group differences for each of the three $\mathrm{NH}$ stress conditions while ensuring that group similarities existed at Baseline and Post Stress conditions. In the presence of such interactions, main effects were not further evaluated because between group differences were the focus of this study. Additionally, appropriate effect sizes are reported

TABLE 3 | MANOVA: 2 (group) $\times 5$ (percent $\mathrm{O}_{2}$ ) $\times 2$ (time) for $\mathrm{SpO}_{2}$ and pulse rate.

\begin{tabular}{|c|c|c|c|c|c|}
\hline Effect & Test statistic & $\begin{array}{l}\text { Degrees of } \\
\text { freedom }\end{array}$ & $\boldsymbol{F}$ & $p$ & $\eta^{2}$ \\
\hline Group main effect & Wilks' $\lambda=0.880$ & 2,69 & 14.85 & $<0.01$ & 0.123 \\
\hline $\begin{array}{l}\text { Percent } \mathrm{O}_{2} \text { main } \\
\text { effect }\end{array}$ & Wilks' $\lambda=0.079$ & 8,63 & 91.71 & $<0.01$ & 0.921 \\
\hline Time main effect & Wilks' $\lambda=0.152$ & 8,69 & 192.96 & $<0.01$ & 0.848 \\
\hline $\begin{array}{l}\text { Group by percent } \mathrm{O}_{2} \\
\text { interaction effect }\end{array}$ & Wilks' $\lambda=0.820$ & 8,63 & 1.73 & 0.11 & 0.180 \\
\hline $\begin{array}{l}\text { Group by time } \\
\text { interaction effect }\end{array}$ & Wilks' $\lambda=0.859$ & 8,69 & 5.66 & $<0.01$ & 0.141 \\
\hline $\begin{array}{l}\text { Percent } \mathrm{O}_{2} \text { by time } \\
\text { interaction effect }\end{array}$ & Wilks' $\lambda=0.104$ & 8,63 & 67.51 & $<0.01$ & 0.896 \\
\hline $\begin{array}{l}\text { Group by percent } \mathrm{O}_{2} \\
\text { by time interaction } \\
\text { effect }\end{array}$ & Wilks' $\lambda=0.667$ & 8,63 & 9.94 & $<0.01$ & 0.333 \\
\hline
\end{tabular}


with each analysis, $\eta^{2}$ for analyses of variance and Cohen's $d$ for $t$-tests.

\section{Procedures Used to Determine the Linear Fit Analyses}

To evaluate group differences over time for $\mathrm{SpO}_{2}$ and pulse rate, the linear line of best fit was determined for each subject in each percent $\mathrm{O}_{2}$ condition for the duration of that condition, but with the first minute excluded from the calculations. These individual slopes and intercepts were averaged over mTBI volunteers and over HC volunteers to generate a group average $( \pm$ SEM $)$ slope and a group average $( \pm \mathrm{SEM})$ intercept for $\mathrm{SpO}_{2}$ and pulse rate. These average regression slopes and intercepts are presented in Table 6. Figures 1 and $\mathbf{2}$ depict the average regression lines and the data, including first and last minute of each condition by group. These values were used in the 2 (group) $\times 5$ (percent $\mathrm{O}_{2}$ ) MANOVA (Table 5) to evaluate the slope and intercept differences between groups.

\section{FIT Correlation with $\mathrm{SpO}_{2}$ and Pulse Rate}

Simple bivariate correlations among the four FIT measures and the two pulse oximeter measures, $\mathrm{SpO}_{2}$ and pulse rate, were determined by group (Table 9 ).

\section{RESULTS}

Figures 1 and 2 show the group average response to each percent $\mathrm{O}_{2}$ condition for each minute of exposure. These figures illustrate the average group response to reduced $\mathrm{O}_{2}$ over the period of exposure. Average $\mathrm{SpO}_{2}$ (Figure 1) for the two groups was the same at the Baseline and the Post Stress conditions. At the beginning of each $\mathrm{NH}$ stress condition, $\mathrm{SpO}_{2}$ for the mTBI and $\mathrm{HC}$ groups was indistinguishable; but with continued hypoxic exposure, $\mathrm{SpO}_{2}$ decreased for both groups, decreasing more for the HC group than the mTBI group. The pulse rate response (Figure 2) tended to increase for both groups from the Baseline condition through the $13 \% \mathrm{O}_{2}$ condition, but a marked drop in pulse rate is evident at the conclusion of the hypoxic exposures, as reflected in the pulse rate recorded at Post Stress.

\section{MANOVA of $\mathrm{SpO}_{2}$ and Pulse Rate}

The 2 (group) $\times 5$ (percent $\left.\mathrm{O}_{2}\right) \times 2$ (time) MANOVA (Table 3 ) was performed to test differences between the MTBI and HC groups at the first and last minute of each condition for the dependent measures, $\mathrm{SpO}_{2}$ and pulse rate. Box's $M$ test of equality of covariance matrices was not significant $[M=328.15, F(210$, $14,975)=1.08, p=0.194]$. Table 3 shows that six of the seven effects were significant.

Results of follow up univariate tests are provided in Table 4. To account for significant Mauchly's test of sphericity, Greenhouse-Geisser corrected univariate tests (e.g., $\left.\chi^{2}=142.94, \mathrm{df}=9, p<0.001\right)$, showed the three-way interaction for group by percent $\mathrm{O}_{2}$ by time was significant for both $\mathrm{SpO}_{2}\left[F(2.17,151.8)=5.29, p<0.001, \eta^{2}=0.852\right]$ and pulse rate $\left[F(3.21,224.8)=3.05, p<0.001, \eta^{2}=0.733\right]$. Follow-up planned comparisons showed mTBI and HC were not statistically different at the first and last minute of each $21 \% \mathrm{O}_{2}$ 
condition and the first minute of the three $\mathrm{NH}$ stress conditions for both $\mathrm{SpO}_{2}\left[F(2.93,204.92)=0.399, p=0.749, \eta^{2}=0.006\right]$ and pulse rate $\left[F(4.83,338.25)=0.598, p=0.696, \eta^{2}=0.008\right]$. These non-significant results indicate that both groups were indistinguishable as they began each $\mathrm{NH}$ stress condition, and that $\mathrm{NH}$ did not have differential lingering aftereffects on the two subject groups.

Further follow-up compared Baseline to the last minute of the three hypoxic stress conditions using $t$-tests to identify group differences within conditions (Table 4). $\mathrm{SpO}_{2}$ was significantly different from Baseline during the last minute of all three reduced percent $\mathrm{O}_{2}$ stress conditions $[F(1.84,128.68)=6.92, p=0.002$, $\left.\eta^{2}=0.090\right]$, with mTBI evidencing significantly higher $\mathrm{SpO}_{2}$ than the controls during the last minute of each condition, specifically $15.5 \% \mathrm{O}_{2}[t(70)=2.55, p=0.013, d=0.481], 14 \%$ $\mathrm{O}_{2}[t(70)=4.09, p<0.001, d=0.834]$, and $13 \% \mathrm{O}_{2}[t(70)=2.29$, $p=0.025, d=0.458]$. For pulse rate, differences between baseline and the last minute of each stress approached significance $\left[F(2.66,186.29)=2.74, p=0.052, \eta^{2}=0.038\right]$, and group pulse rate differences only emerged during the last minute of $14 \%$ $\mathrm{O}_{2}$ and approached significances at $13 \% \mathrm{O}_{2}$; specifically $15.5 \%$ $\mathrm{O}_{2}[t(70)=1.24, p=0.218, d=0.253], 14 \% \mathrm{O}_{2}[t(70)=2.17$, $p=0.034, d=0.511]$, and $13 \% \mathrm{O}_{2}[t(70)=1.81, p=0.075$, $d=0.362]$.

TABLE 5 | MANOVA: 2 (group) $\times 5$ (percent $\mathrm{O}_{2}$ ) for slope and intercept of $\mathrm{SpO}_{2}$ and pulse rate.

\begin{tabular}{llcrrrr}
\hline Effect & Test statistic & $\begin{array}{l}\text { Degrees of } \\
\text { freedom }\end{array}$ & $\boldsymbol{F}$ & $\boldsymbol{p}$ & $\boldsymbol{\eta}^{2}$ \\
\hline Group main effect & Pillai's trace $=0.178$ & 4,67 & 3.64 & $<0.01$ & 0.178 \\
Percent $\mathrm{O}_{2}$ main effect & Pillai's trace $=0.955$ & 16,55 & 72.53 & $<0.01$ & 0.955 \\
Group by percent $\mathrm{O}_{2}$ & Pillai's trace $=0.261$ & 16,55 & 1.22 & 0.29 & 0.001
\end{tabular}

\section{MANOVA of $\mathrm{SpO}_{2}$ and Pulse Rate Slope and Intercept}

A 2 (group) $\times 5$ (percent $\mathrm{O}_{2}$ ) MANOVA (Table 5) evaluated the slope and intercept of the $\mathrm{SpO}_{2}$ and pulse rate responses throughout each condition. Box's $M$ test of equality of covariance matrices was significant $[M=365.36, F(210,14,975)=1.21, p=0.022]$, which indicated that the assumption of equivalent covariance across groups was not met; consequently, Pillai's trace was used to control for Type-I error. Table 5 shows that the main effect of group and of percent $\mathrm{O}_{2}$ condition was significant, but there was no interaction between these variables. The main effects emerged significant but the group by percent $\mathrm{O}_{2}$ interaction was not.

Follow-up test results are provided in Table 6. Follow-up planned comparisons showed the groups were not statistically different at the two $21 \% \mathrm{O}_{2}$ conditions for $\mathrm{SpO}_{2}$ slope $[F(1,70)=0.091$, $\left.p=0.764, \eta^{2}=0.001\right], \mathrm{SpO}_{2}$ intercept $[F(1,70)=0.057, p=0.812$, $\left.\eta^{2}=0.001\right]$, pulse rate slope $\left[F(1,70)=0.003, p=0.956, \eta^{2}=0.001\right]$, and pulse rate intercept $\left[F(1,70)=0.079, p=0.780, \eta^{2}=0.001\right]$. These non-significant results indicated that both groups were initially indistinguishable and did not differentially experience lingering effects of $\mathrm{NH}$. These results also show that the main effects for percent $\mathrm{O}_{2}$ reported in Table 6 are not attributable to differences at the two equivalent conditions of Baseline and Post Stress.

Although the omnibus group by percent $\mathrm{O}_{2}$ interaction failed to reach significance, univariate follow-up tests, using Greenhouse-Geisser correction to account for a significant Mauchly's test of sphericity, showed that the non-significant MANOVA masked a single significant interaction for $\mathrm{SpO}_{2}$ slope $\left[F(2.3,161.3)=2.863, p<0.001, \eta^{2}=0.569\right]$ (see Table 6). Follow-up $t$-tests for $\mathrm{SpO}_{2}$ slope revealed the mTBI group had shallower slopes than the $\mathrm{HC}$ group for each $\mathrm{NH}$ stress condition, specifically $15.5 \% \mathrm{O}_{2}[t(70)=3.09, p=0.003, d=0.564], 14 \% \mathrm{O}_{2}$ $[t(70)=2.23, p=0.029, d=0.482]$, and $13 \% \mathrm{O}_{2}[t(70)=2.27$, $p=0.026, d=0.456]$.

TABLE 6 | Means and SEM by subject group for $\mathrm{SpO}_{2}$ and pulse rate regression slopes and intercepts.

\begin{tabular}{|c|c|c|c|c|c|}
\hline & $21 \% \mathrm{O}_{2}$ baseline & $15.5 \% \mathrm{O}_{2}$ & $14 \% \mathrm{O}_{2}$ & $13 \% \mathrm{O}_{2}$ & $21 \% \mathrm{O}_{2}$ post stres \\
\hline $\mathrm{SpO}_{2}$ slope & \multicolumn{5}{|c|}{ Group $p<0.001$, Percent $\mathrm{O}_{2} p<0.001$, Group $\times$ Percent $\mathrm{O}_{2} p<0.001^{\star *}$} \\
\hline $\begin{array}{l}\text { mTBI } \\
\mathrm{HC}\end{array}$ & $\begin{array}{l}-0.01 \pm 0.01 \\
-0.01 \pm 0.01\end{array}$ & $\begin{array}{l}-0.06 \pm 0.02^{+, \neq}, \\
-0.14 \pm 0.02^{+, \neq}\end{array}$ & $\begin{array}{l}-0.21 \pm 0.03^{\dagger, \neq} \\
-0.34 \pm 0.07^{+, \neq}\end{array}$ & $\begin{array}{l}-0.25 \pm 0.05^{\dagger, \neq} \\
-0.44 \pm 0.07^{t, \neq}\end{array}$ & $\begin{array}{l}+0.04 \pm 0.02 \\
+0.04 \pm 0.02\end{array}$ \\
\hline $\mathrm{SpO}_{2}$ intercept & \multicolumn{5}{|c|}{ Group $p=0.097$, Percent $\mathrm{O}_{2} p<0.001$, Group $\times$ Percent $\mathrm{O}_{2} p=0.12^{\star \star}$} \\
\hline $\begin{array}{l}\mathrm{mTBI} \\
\mathrm{HC}\end{array}$ & $\begin{array}{l}97.2 \pm 0.09 \\
97.0 \pm 0.10\end{array}$ & $\begin{array}{l}94.1 \pm 0.28 \\
93.9 \pm 0.24\end{array}$ & $\begin{array}{l}94.1 \pm 0.28^{\dagger} \\
93.9 \pm 0.24^{\dagger}\end{array}$ & $\begin{array}{l}87.4 \pm 0.57 \\
86.3 \pm 0.46\end{array}$ & $\begin{array}{l}96.6 \pm 0.21 \\
96.5 \pm 0.24\end{array}$ \\
\hline Pulse rate slope & \multicolumn{5}{|c|}{ Group $p=0.709$, Percent $\mathrm{O}_{2} p<0.001$, Group $\times$ Percent $\mathrm{O}_{2} p=0.82^{\star \star}$} \\
\hline $\begin{array}{l}\mathrm{mTBI} \\
\mathrm{HC}\end{array}$ & $\begin{array}{l}0.19 \pm 0.07 \\
0.13 \pm 0.08\end{array}$ & $\begin{array}{l}-0.07 \pm 0.09 \\
-0.08 \pm 0.10\end{array}$ & $\begin{array}{l}0.15 \pm 0.08 \\
0.07 \pm 0.10\end{array}$ & $\begin{array}{l}0.27 \pm 0.09^{\dagger} \\
0.34 \pm 0.10^{\dagger}\end{array}$ & $\begin{array}{l}0.36 \pm 0.07 \\
0.29 \pm 0.09\end{array}$ \\
\hline Pulse rate intercept & \multicolumn{5}{|c|}{ Group $p=0.131$, Percent $\mathrm{O}_{2} p<0.001$, Group $\times$ Percent $\mathrm{O}_{2} p=0.73^{\star \star}$} \\
\hline $\begin{array}{l}\text { mTBI } \\
\mathrm{HC}\end{array}$ & $\begin{array}{l}71.9 \pm 1.80 \\
75.6 \pm 1.90\end{array}$ & $\begin{array}{l}76.2 \pm 1.90 \\
80.4 \pm 2.20\end{array}$ & $\begin{array}{l}75.7 \pm 1.80^{\dagger} \\
81.3 \pm 2.00^{+}\end{array}$ & $\begin{array}{l}75.3 \pm 1.90^{\dagger} \\
80.1 \pm 2.10^{+}\end{array}$ & $\begin{array}{l}65.7 \pm 1.80 \\
69.0 \pm 2.00\end{array}$ \\
\hline
\end{tabular}

${ }^{* *}$ Greenhouse-Geisser correction was used in the univariate ANOVA follow-ups to account for significant Mauchly's test of sphericity with Epsilon values $<0.75$. Overall, SpO ${ }_{2}$ results were stronger than the pulse rate results and only relevant interactions effects are identified. Main effects were not considered important because $m T B I$ and $H C$ were matched pairs and the Baseline and Post stress were expected to be equivalent. Follow-up $t$-tests for the significant $\mathrm{SpO}_{2}$ interaction show the mTBI group had shallower slopes than the HCs and both groups had steeper slopes than the $21 \% \mathrm{O}_{2}$ conditions.

+Significantly different from Baseline $(p<0.05)$.

${ }^{\ddagger}$ Significant group difference at the specified percent $\mathrm{O}_{2}$ condition $(p<0.05)$. 


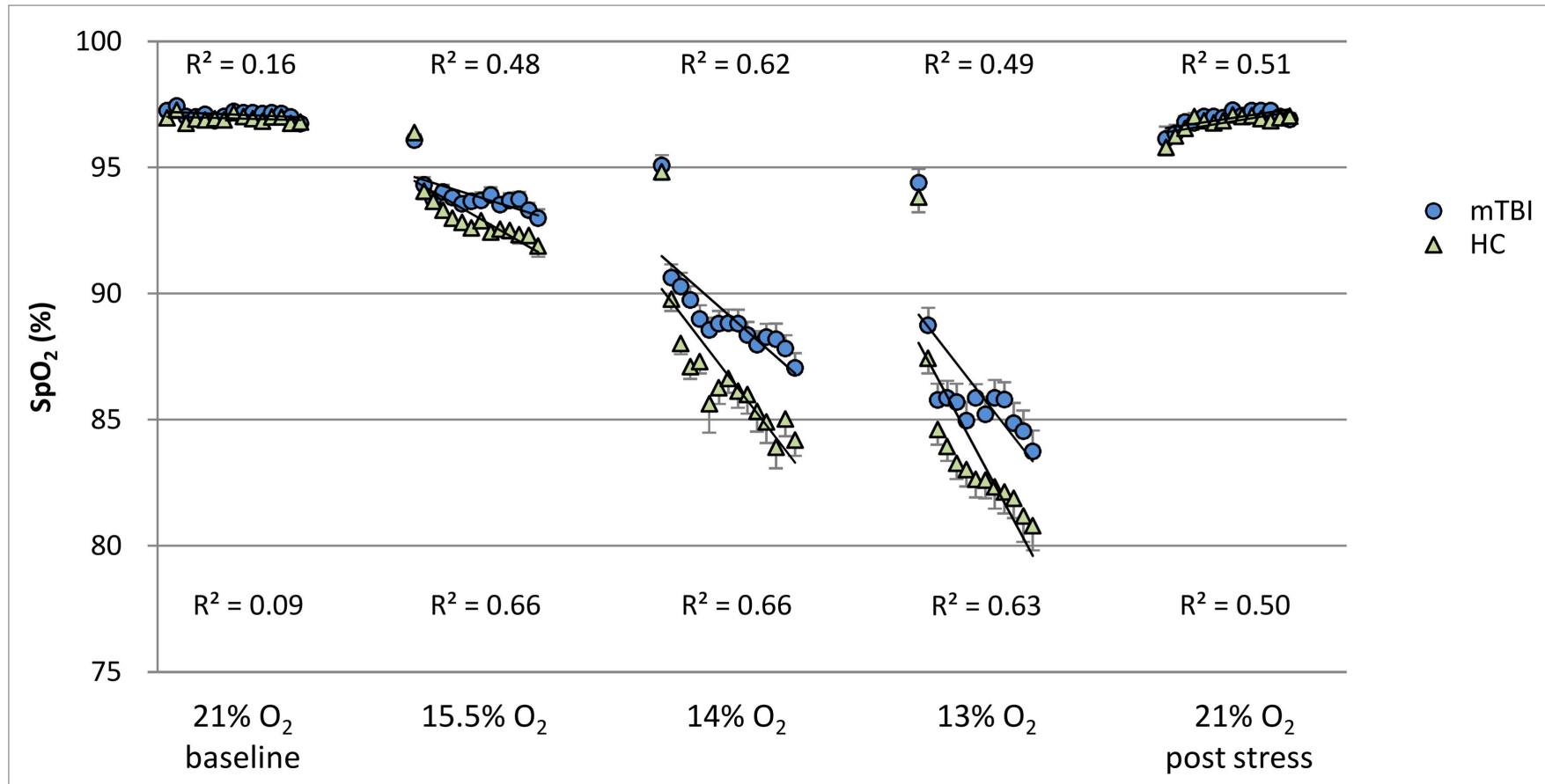

FIGURE 1 | SpO 2 : minute by minute group average and SEM for each percent $\mathrm{O}_{2}$ condition. Note: $\mathrm{R}^{2}$ values are for the linear line of best fit for each group at each percent $\mathrm{O}_{2}$ condition.

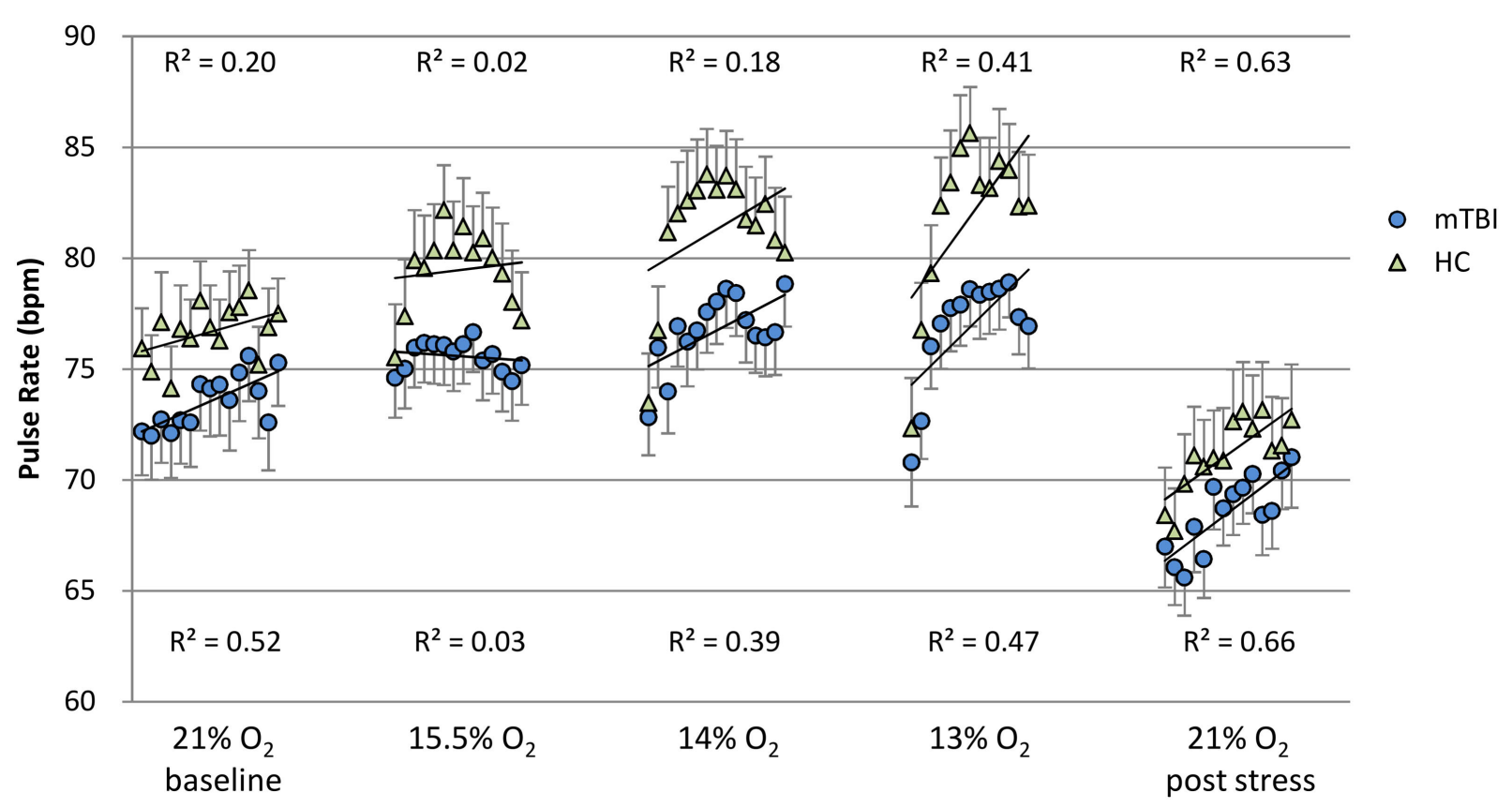

FIGURE 2 | Pulse rate: minute by minute group average and SEM for each percent $\mathbf{O}_{2}$ condition. Note: $\mathrm{R}^{2}$ values are for the linear line of best fit for each group at each percent $\mathrm{O}_{2}$ condition.

\section{Oculometrics}

\section{MANOVA FIT Outcome Measures}

A 2 (group) $\times 5$ (percent $\mathrm{O}_{2}$ ) MANOVA evaluated the four FIT outcome measures (pupil diameter, pupil constriction amplitude, pupil latency, and saccadic velocity). Box's $M$ test of equality of covariance matrices was not significant $[M=361.95, F(210$, $11,650)=1.123, p=0.109]$, indicating the assumption of equivalent covariance across groups was not violated. The MANOVA 
for FIT outcomes emerged with a significant percent $\mathrm{O}_{2}$ effect (Table 7), showing an effect of NH on the FIT measures, an effect that was not different between subject groups and thus has little bearing on the purposes of the present experiment. Confirming the non-significant omnibus interaction, none of the univariate interaction effects emerged significant (see Table 8).

\section{Correlation of FIT Outcomes with $\mathrm{SpO}_{2}$ and Pulse Rate}

Simple bivariate correlations among the FIT outcome measures and $\mathrm{SpO}_{2}$ and pulse rate were determined for both groups (Table 9). Although four relationships emerged significant, Pearson's $r$ indicated weak relationships.

\section{DISCUSSION}

The three levels of $\mathrm{NH}$ stress used in this study produced $\mathrm{SpO}_{2}$ and pulse rate responses that differed between the mTBI and matched $\mathrm{HC}$ groups. However, $\mathrm{SpO}_{2}$ and pulse rate were indistinguishable between mTBI and $\mathrm{HC}$ groups during Baseline, at the initiation of each $\mathrm{NH}$ stress condition, and during the Post NH Stress condition. Thus, consistent with previous stress and mTBI research involving physiological metrics, the mTBI group was not different from the matched $\mathrm{HC}$ group when not stressed.

TABLE 7 | MANOVA: 2 (group) $\times \mathbf{5}$ (percent $\mathrm{O}_{2}$ ) for FIT outcome measures.

\begin{tabular}{|c|c|c|c|c|c|}
\hline Effect & Test statistic & $\begin{array}{l}\text { Degrees of } \\
\text { freedom }\end{array}$ & $F$ & $p$ & $\eta^{2}$ \\
\hline Group main effect & Wilks' $\lambda=0.893$ & 4,59 & 1.76 & 0.19 & 0.107 \\
\hline Percent $\mathrm{O}_{2}$ main effect & Wilks' $\lambda=0.365$ & 16,47 & 5.11 & $<0.01$ & 0.635 \\
\hline Group by percent $\mathrm{O}_{2}$ & Wilks' $\lambda=0.730$ & 16,47 & 1.09 & 0.39 & 0.270 \\
\hline
\end{tabular}

interaction effect
In mammals, $\mathrm{SpO}_{2}$ normally decreases with reduced inspired $\mathrm{O}_{2}$ concentrations. The findings reported here showed the mTBI group had $\mathrm{SpO}_{2}$ values that were consistently higher, i.e., less reduced, than the $\mathrm{HCs}$ throughout each $\mathrm{NH}$ stress condition. Furthermore, at a constant percent $\mathrm{O}_{2}$, the falloff in $\mathrm{SpO}_{2}$ over time was less for the mTBI than for the $\mathrm{HC}$ group (Figure 1). These findings, the first to compare $\mathrm{SpO}_{2}$ between mTBI and $\mathrm{HC}$ groups under $\mathrm{NH}$ in humans, may seem counterintuitive. However, it may be noted that a normal response to hypoxia is an increase in ventilation, the hypoxic hyperventilatory response (HVR). An increased HVR in the mTBI group could account for the increase in $\mathrm{SpO}_{2}$ relative to the HC group and such a differential effect on the HVR may reflect changes associated with $\mathrm{mTBI}$ in the autonomic and cardiovascular systems (30). Furthermore, the observation that pulse rate trended lower in the hypoxic mTBI subjects than in hypoxic HC would also be consistent with an increased HVR in the mTBI group. The report by Len et al. (5) that $\mathrm{PETCO}_{2}$ is lower in the mTBI group than HC group when breath holding

TABLE 9 | Correlation among FIT outcome measures and $\mathrm{SpO}_{2}$ and pulse rate.

\begin{tabular}{|c|c|c|c|c|c|c|c|c|}
\hline \multirow[t]{2}{*}{ Group } & \multicolumn{2}{|c|}{$\begin{array}{c}\text { Pupil } \\
\text { diameter }\end{array}$} & \multicolumn{2}{|c|}{$\begin{array}{c}\text { Pupil } \\
\text { constriction } \\
\text { amplitude }\end{array}$} & \multicolumn{2}{|c|}{$\begin{array}{c}\text { Pupil } \\
\text { constriction } \\
\text { latency }\end{array}$} & \multicolumn{2}{|c|}{$\begin{array}{l}\text { Saccadic } \\
\text { velocity }\end{array}$} \\
\hline & $r$ & $p$ & $r$ & $p$ & $r$ & $p$ & $r$ & $p$ \\
\hline \multicolumn{9}{|l|}{$\mathrm{SpO}_{2}$} \\
\hline mTBI & 0.108 & 0.15 & 0.105 & 0.17 & -0.003 & 0.97 & 0.118 & 0.11 \\
\hline $\mathrm{HC}$ & $0.169^{\star}$ & 0.02 & $0.250^{\star}$ & 0.01 & -0.076 & 0.32 & 0.076 & 0.31 \\
\hline \multicolumn{9}{|c|}{ Pulse rate } \\
\hline mTBI & -0.071 & 0.35 & -0.016 & 0.833 & 0.036 & 0.637 & -0.123 & 0.10 \\
\hline $\mathrm{HC}$ & $0.288^{\star}$ & 0.01 & -0.027 & 0.72 & 0.087 & 0.25 & $0.170^{\star}$ & 0.02 \\
\hline
\end{tabular}

TABLE 8 | Group by condition means and SEM for each of the four FIT-dependent measures.

\begin{tabular}{|c|c|c|c|c|c|}
\hline & $21 \% \mathrm{O}_{2}$ baseline & $15.5 \% \mathrm{O}_{2}$ & $14 \% \mathrm{O}_{2}$ & $13 \% \mathrm{O}_{2}$ & $21 \% \mathrm{O}_{2}$ post stress \\
\hline Pupil diameter & \multicolumn{5}{|c|}{ Group $p=0.066$, Percent $\mathrm{O}_{2} p<0.001$, Group $\times$ Percent $\mathrm{O}_{2} p=0.617^{\star \star}$} \\
\hline $\mathrm{mTBI}$ & $5.42 \pm 0.46$ & $5.29 \pm 0.16$ & $5.17 \pm 0.16$ & $5.08 \pm 0.17$ & $5.19 \pm 0.15$ \\
\hline $\mathrm{HC}$ & $5.87 \pm 0.16$ & $5.68 \pm 0.16$ & $5.59 \pm 0.16$ & $5.43 \pm 0.17$ & $5.66 \pm 0.16$ \\
\hline Pupil constriction amplitude & \multicolumn{5}{|c|}{ Group $p=0.618$, Percent $\mathrm{O}_{2} p<0.001$, Group $\times$ Percent $\mathrm{O}_{2} p=0.391^{\star \star}$} \\
\hline mTBI & $1.13 \pm 0.04$ & $1.12 \pm 0.04$ & $1.10 \pm 0.04$ & $1.06 \pm 0.04$ & $1.11 \pm 0.04$ \\
\hline $\mathrm{HC}$ & $1.19 \pm 0.04$ & $1.14 \pm 0.04$ & $1.10 \pm 0.04$ & $1.06 \pm 0.04$ & $1.16 \pm 0.04$ \\
\hline Pupil constriction latency & \multicolumn{5}{|c|}{ Group $p=0.252$, Percent $\mathrm{O}_{2} p=0.276$, Group $\times$ Percent $\mathrm{O}_{2} p=0.680^{\star *}$} \\
\hline mTBI (ms) & $299.97 \pm 4.04$ & $298.28 \pm 3.82$ & $301.27 \pm 3.87$ & $299.85 \pm 3.91$ & $303.02 \pm 4.10$ \\
\hline $\mathrm{HC}(\mathrm{ms})$ & $294.22 \pm 4.17$ & $293.71 \pm 3.94$ & $295.24 \pm 4.00$ & $293.57 \pm 4.04$ & $294.44 \pm 4.24$ \\
\hline Saccadic velocity & \multicolumn{5}{|c|}{ Group $p=0.685$, Percent $\mathrm{O}_{2} p<0.001$, Group $\times$ Percent $\mathrm{O}_{2} p=0.091^{\star \star}$} \\
\hline mTBI (ms) & $74.25 \pm 1.21$ & $72.47 \pm 1.29$ & $72.96 \pm 1.18$ & $72.06 \pm 1.33$ & $71.67 \pm 1.34$ \\
\hline $\mathrm{HC}(\mathrm{ms})$ & $72.32 \pm 1.25$ & $73.64 \pm 1.33$ & $71.99 \pm 1.22$ & $71.01 \pm 1.37$ & $71.02 \pm 1.38$ \\
\hline
\end{tabular}

**Greenhouse-Geisser correction was used in the univariate ANOVA follow-ups to account for significant Mauchly's test of sphericity with Epsilon values < 0.75. Main effects were

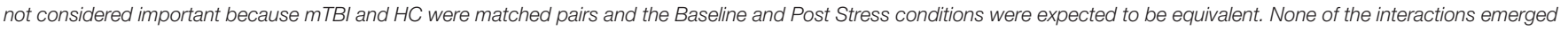
significant. 
and when hyperventilating seems consistent with this idea. Unfortunately, a broader set of respiration measures (e.g., $\mathrm{ETO}_{2}$, respiration rate, minute ventilation, and total volume of gas expired per condition) was not collected in either the present study nor reported by Len et al. Exploring the relationships among blood oxygenation and respiration in those with a history of mTBI who are currently asymptomatic and appear to have fully recovered from injury is necessary to further explore the latent impact of brain injury.

On the other hand, the $\mathrm{SpO}_{2}$ differences reported here could possibly occur because of differences in physical fitness between the two subject groups, with the mTBI group being more physically fit than the HC group. However, this seems unlikely since the HCs were selected to ensure the groups did not differ statistically along the dimensions of age, height, BMI, systolic and diastolic blood pressure, pulse rate, or respiration rate; moreover, the pulse rate response was not significantly different between groups.

It may be noted that the pulse rate recorded during Post Stress (Figure 2), while not statistically different between the mTBI and HC groups, was statistically significantly less than the pulse rate recorded during the Baseline, despite the fact that neither condition posed any hypoxic stress. This significant decrease in pulse rate immediately following the conclusion of the $13 \% \mathrm{O}_{2}$ is consistent with previous findings reported in the literature. Roche et al. (31) measured cardiovascular response in a group of healthy volunteers before, during, and after a 15-min hypoxic exposure with $11 \% \mathrm{O}_{2}$ stress and reported that heart rate increased $19 \%$ over the initial baseline during hypoxia; but more interesting, during the 15 -min recovery period heart rate decreased $10 \%$ below baseline. The methods used by Roche et al., which included measures of HRV, assessed the autonomic nervous system and pointed to an exaggerated sympathetic response to $\mathrm{NH}$ followed by an enhanced parasympathetic response during the recovery period, which is completely consistent with the findings reported here.

The FIT showed sensitivity to hypoxia as noted in Table 8; the main effects for $\mathrm{NH}$ stress were significant for diameter and response amplitude of the pupil and saccadic velocity. The main effect for NH stress was consistent with the study by Cymerman et al. (17), which showed changes in pupil diameter, response amplitude, and latency but without changes in saccadic velocity following $3 \mathrm{~h}$ of continuous exposure to an altitude of 4,300 $\mathrm{m}(14,107 \mathrm{ft})$. However, since the FIT failed to show differences between the mTBI and HC groups it is possible that there are, in fact, no differences in the ocular motor behavior between the two subject groups; but based on the emerging scientific literature describing oculometrics in mTBI $(12,22,32-34)$, it seems more likely that the FIT was merely insufficiently sensitive to differences that do exist. It should be noted that the FIT was designed as a non-invasive, oculomotor, performance-based fitness for duty impairment screener, and as such, the FIT may simply have been inadequate for the purposes of this research.

Normobaric hypoxia did not produce undesirable physiological outcomes in the mTBI subjects in this study. $\mathrm{SpO}_{2}$ and pulse rate values did change with increased $\mathrm{NH}$; however, values did not approach limits considered to be dangerous to health. Also, no trial had to be stopped due to health concerns or extreme discomfort experienced by the subjects. Unlike the breathing behavior alterations used by Len et al. $(5,6)$, the ROBD produces a sustained physiological stress and affords the opportunity to administer additional tests under a range of constant NH stress levels. These effects were reversed and disappeared when the subjects were returned to sea level and room air. Our results are consistent with the findings reported by Ewing et al.; individuals with a history of mTBI may be particularly susceptible to the effects of mild or moderate hypoxia. The hypobaric hypoxic research paradigm that Ewing et al. (9) used requires a significant infrastructure to support. The $\mathrm{NH}$ method used here is portable, and by comparison with the hypobaric paradigm, is safe, inexpensive, and easy to create in most laboratory or clinical settings.

It is important to acknowledge limitations of the present study. One important limitation was the wide range of the time between a volunteer's trauma and test participation, a range from 1.7 to 119.7 months. The elapsed time since injury was not controlled. Second, physical activity level (e.g., hours per week) or fitness level $\left(\mathrm{VO}_{2} \max \right)$ were not used in the matching criteria between subjects. Third, the pulse oximeter data were very limited, recorded once a minute by hand. Finally, the history of brain injury was determined by self-report. It is possible that individual subjects were not accurate about their brain injury history, a limitation that could be present in both groups.

\section{CONCLUSION}

When exposed to mild or moderate normobaric hypoxic stress conditions simulating altitudes up to $14,000 \mathrm{ft}$ above MSL: (1) peripheral oxygen saturation $\left(\mathrm{SpO}_{2}\right)$ differences emerged between the mTBI and matched HCs, (2) pulse rate trended lower in the mTBI group, and (3) FIT oculometrics were not sensitive to group differences. These findings demonstrate that a relatively minor hypoxic challenge can reveal measurable differences in $\mathrm{SpO}_{2}$ and pulse rate but not FIT measures, in otherwise asymptomatic individuals with a history of mTBI.

\section{AUTHOR CONTRIBUTIONS}

LT had overall responsibility of the project. PS was primary lead on data analysis and an equal contributor to manuscript writing. JB was an equal contributor on data analysis, interpretation, and manuscript writing.

\section{FUNDING}

This research was supported in part by the Congressionally Directed Medical Research Program TBI, PTSD Programs Award Number W81XWH-08-2-0052 PTO75175: the effects of hypoxia on cognitive function in aviators and complex system operators that have had a mild traumatic brain injury. 


\section{REFERENCES}

1. McCrory P, Meeuwisse WH, Aubry M, Cantu RC, Dvorak J, Echemendia RJ, et al. Consensus statement on concussion in sport: the 4th International Conference on Concussion in Sport, Zurich, November 2012. Br J Sports Med (2013) 47(5):250-8. doi:10.1136/bjsports-2013-092313

2. Hanna-Pladdy B, Berry ZM, Bennett T, Phillips HL, Gouvier WD. Stress as a diagnostic challenge for postconcussive symptoms: sequelae of mild traumatic brain injury or physiological stress response. Clin Neuropsychol (2001) 15(3):289-304. doi:10.1076/clin.15.3.289.10272

3. Gall B, Parkhouse WS, Goodman D. Heart rate variability of recently concussed athletes at rest and exercise. Med Sci Sports Exerc (2004) 36(8):1269-74. doi:10.1249/01.MSS.0000135787.73757.4D

4. King ML, Lichtman SW, Seliger G, Ehert FA, Steinberg JS. Heart-rate variability in chronic traumatic brain injury. Brain Inj (1997) 11(6):445-53. doi:10.1080/026990597123421

5. Len TK, Neary JP. Cerebrovascular pathophysiology following mild traumatic brain injury. Clin Physiol Funct Imaging (2011) 31(2):85-93. doi:10.1111/j.1475-097X.2010.00990.x

6. Len TK, Neary JP, Asmundson GJ, Candow DG, Goodman DG, Bjornson B, et al. Serial monitoring of $\mathrm{CO}_{2}$ reactivity following sport concussion using hypocapnia and hypercapnia. Brain Inj (2013) 27(3):346-53. doi:10.3109/ 02699052.2012 .743185

7. Gall B, Parkhouse WS, Goodman D. Exercise following a sport induced concussion. Br J Sports Med (2004) 38(6):773-7. doi:10.1136/ bjsm.2003.009530

8. Baker JM, Good DE. Physiological emotional under-arousal in individuals with mild head injury. Brain Inj (2014) 28(1):51-65. doi:10.3109/02699052. 2013.857787

9. Ewing R, McCarthy D, Gronwall D, Wrightson P. Persisting effects of minor head injury observable during hypoxic stress. J Clin Exp Neuropsychol (1980) 2(2):147-55. doi:10.1080/01688638008403789

10. Temme LA, Bleiberg J, Reeves D, Still DL, Levinson D, Browning R. Uncovering latent deficits due to mild traumatic brain injury by using normobaric hypoxia stress. Front Neurol (2013) 4:41. doi:10.3389/ fneur.2013.00041

11. Temme LA, Still DL, Reeves D, Bleiberg J, Levinson D, Kelly J. Normobaric Hypoxia as a Cognitive Stress Test for Mild Traumatic Brain Injury: Oculometrics, Pulse Oximetry, and the Self-Report of Symptom Severity. (USAARL-2016-15). Fort Rucker, AL: U.S. Army Aeromedical Research Laboratory (2016).

12. Cifu DX, Wares JR, Hoke KW, Wetzel PA, Gitchel G, Carne W. Differential eye movements in mild traumatic brain injury versus normal controls. J Head Trauma Rehabil (2015) 30(1):21-8. doi:10.1097/HTR.0000000000000036

13. Kardon RH. Regulation of light through the pupil. 11th ed. In: Levine LA, Nilsson SFE, Hoeve JV, Wu SM, editors. Adler's Physiology of the Eye. Edinburgh: Saunders Elsevier (2011). p. 502-26.

14. Leigh RJ, Zee DS. The Neurology of Eye Movements. Oxford: Oxford University Press (2006).

15. Suchoff I, Ciuffreda K, Kapoor N, editors. Visual and Vestibular Consequences of Acquired Brain Injury. Santa Ana, CA: Optometric Extension Program Foundation, Inc. (2001).

16. Balkin TJ, Bliese PD, Belenky G, Sing H, Thorne DR, Thomas M, et al. Comparative utility of instruments for monitoring sleepiness-related performance decrements in the operational environment. J Sleep Res (2004) 13(3):219-27. doi:10.1111/j.1365-2869.2004.00407.x

17. Cymerman A, Muza SR, Friedlander AL, Fulco CS, Rock PB. Saccadic velocity and pupillary reflexes during acclimatization to altitude $(4300 \mathrm{~m})$. Aviat Space Environ Med (2005) 76(7):627-34.

18. LeDuc P, Grieg J, Dunnond S. Self-Report and Ocular Measures of Fatigue in U. S. Army Apache Aviators following flight. (USAARL-2005-10). Fort Rucker, AL: U.S. Army Aeromedical Research Laboratory (2005).
19. Portman-Tiller CA. Fitness Impairment Test (FIT): A First Look. (NAMRL1401). Pensacola, FL: U.S. Naval Aerospace Medical Research Laboratory (1998).

20. Rotherberg N, Cornsweet T, Rafal M. Fitness impairment tester. US Patent No: 5,422,690. (1995).

21. Watson A, Miller L, Lorenz C, Latman S. Evaluation of validity of the PMI FIT 2000-3 fitness-for-duty/impairment screener. J Clin Eng (2006) 31(4):206-12. doi:10.1097/00004669-200610000-00014

22. Capo-Aponte JE, Urosevich TG, Walsh DV, Temme LA, Tarbett AK. Pupillary light reflex as an objective biomarker for early identification of blast-induced mTBI. J Spine (2013) S4:2. doi:10.4172/2165-7939.S4-004

23. McAlister T. Mild brain injury. 2nd ed. In: Silver JM, McAlister TW, Yudofsky SC, editors. Textbook of Traumatic Brain Injury. Washington, DC: American Psychiatric Publishing, Inc. (2011). p. 239-64.

24. Teasdale G, Jennett B. Assessment of coma and impaired consciousness: a practical scale. Lancet (1974) 304(7872):81-4. doi:10.1016/ S0140-6736(74)91639-0

25. Millet GP, Faiss R, Pialoux V. Point: hypobaric hypoxia induces different physiological responses from normobaric hypoxia. JAppl Physiol (2012) 112(10):1783-4. doi:10.1152/japplphysiol.00067.2012

26. Sausen KP, Bower EA, Stiney ME, Feigl C, Wartman R, Clark JB. A closed-loop reduced oxygen breathing device for inducing hypoxia in humans. Aviat Space Environ Med (2003) 74(11):1190-7.

27. Sausen KP, Wallick MT, Slobodnik B, Chimiak JM, Bower EA, Stiney ME, et al. The reduced oxygen breathing paradigm for hypoxia training: physiological, cognitive, and subjective effects. Aviat Space Environ Med (2001) 72(6):539-45.

28. Still DL, Temme LA. An independent, objective calibration check for the reduced oxygen breathing device. Aviat Space Environ Med (2012) 83(9):902-8. doi:10.3357/ASEM.3046.2012

29. Rowland LM, Thomas ML, Thorne DR, Sing HC, Krichmar JL, Davis HQ, et al. Oculomotor responses during partial and total sleep deprivation. Aviat Space Environ Med (2005) 76(7 Suppl):C104-13.

30. Goldstein B, Toweill D, Lai S, Sonnenthal K, Kimberly B. Uncoupling of the autonomic and cardiovascular systems in acute brain injury. Am JPhysiol (1998) 275(4):R1287-92.

31. Roche F, Reynaud C, Garet M, Pichot V, Costes F, Barthelemy JC. Cardiac baroreflex control in humans during and immediately after brief exposure to simulated high altitude. Clin Physiol Funct Imaging (2002) 22(5):301-6. doi:10.1046/j.1475-097X.2002.00434.x

32. Heitger MH, Anderson TJ, Jones RD. Saccade sequences as markers for cerebral dysfunction following mild closed head injury. Prog Brain Res (2002) 140:433-48. doi:10.1016/S0079-6123(02)40067-2

33. Maruta J, Lee SW, Jacobs EF, Ghajar J. A unified science of concussion. Ann N Y Acad Sci (2010) 1208(1):58-66. doi:10.1111/j.1749-6632.2010.05695.x

34. Maruta J, Suh M, Niogi SN, Mukherjee P, Ghajar J. Visual tracking synchronization as a metric for concussion screening. J Head Trauma Rehabil (2010) 25(4):293-305. doi:10.1097/HTR.0b013e3181e67936

Disclaimer: The opinions, interpretations, conclusions, and recommendations are those of the authors and are not necessarily endorsed by the U.S. Army and/or the Department of Defense.

Conflict of Interest Statement: The authors declare that the research was conducted in the absence of any commercial or financial relationships that could be construed as a potential conflict of interest.

Copyright (c) 2016 Temme, St. Onge and Bleiberg. This is an open-access article distributed under the terms of the Creative Commons Attribution License (CC BY). The use, distribution or reproduction in other forums is permitted, provided the original author(s) or licensor are credited and that the original publication in this journal is cited, in accordance with accepted academic practice. No use, distribution or reproduction is permitted which does not comply with these terms. 